\title{
Photophysics and Electrochemiluminescence of Bright Cyclometalated Ir(III) Complexes in Aqueous Solutions
}

Jesus M. Fernandez-Hernandez, ${ }^{\dagger}, \#$ Elena Longhi, ${ }^{\dagger, \$}$ Robert Cysewski, ${ }^{\ddagger}$ Federico Polo, ${ }^{\dagger, \|}$

Hans-Peter Josel, ${ }^{*} \neq$ and Luisa De Cola ${ }^{*, t, \S}$

${ }^{\dagger}$ Westfälische Wilhelms-Universität, Center for Nanotechnology (CeNTech), Heisenbergstrasse 11, 48149 Münster, Germany

${ }^{\ddagger}$ Roche Diagnostics GmbH, Nonnenwald 2, 82372 Penzberg, Germany

Supporting Information

ABSTRACT: A family of neutral bis-cyclometalated iridium complexes $\left[\operatorname{Ir}\left(\mathrm{C}^{\wedge} \mathrm{N}\right)_{2}(\mathrm{LX})\right]$ has been investigated as $\mathrm{ECL}$ labels under immunoassay conditions. Among them, the complex based on phenylphenanthridine (pphent) as the $\mathrm{C}^{\wedge} \mathrm{N}$ ligand, exhibits outstanding performance and it is a candidate to substitute the commercially available Ru-based label in diagnostics.

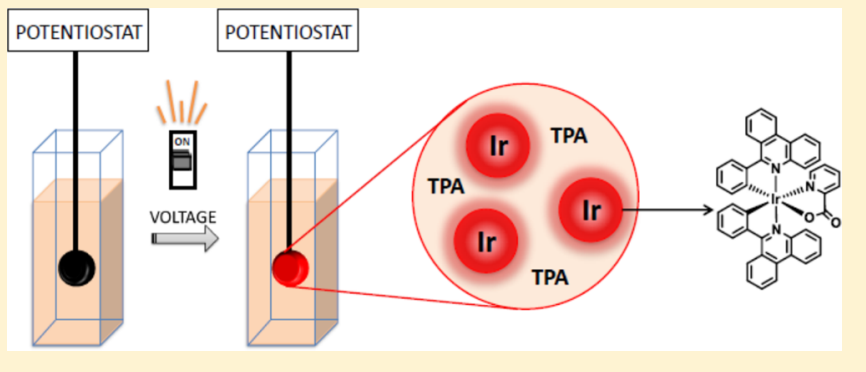

$\mathrm{E}$ lectrochemiluminescence (ECL) is the process whereby species generated at electrodes and chemical species present in solution undergo high-energy electron-transfer reactions to form emissive excited states. As a detection tool, it brings together the advantages of the luminescence techniques with a higher sensitivity also due to the absence of light excitation. ${ }^{1}$ Despite the variety of ECL procedures reported so far, ${ }^{2}$ the most used and studied is based on the well-known ruthenium trisbipyridine complex, $\left[\mathrm{Ru}(\mathrm{bpy})_{3}\right]^{2+}$, as emitter and tri- $N$-propylamine (TPA) as coreactant, and it exhibits ECL efficiency in aqueous media. ${ }^{3}$ This system is the base for many commercially available bio- and immunoassays, food and water testing, or DNA sequences detection. ${ }^{1}$ However, higher sensitivity of ECL assays and different emission colors are desirable due to the increasing demand for accuracy and multiplexing in diagnostics. Thus, many attempts have been carried out to improve ECL efficiency. ${ }^{2}$ One promising strategy is to replace $\left[\mathrm{Ru}(\mathrm{bpy})_{3}\right]^{2+}$ by cyclometalated $\operatorname{Ir}(\mathrm{III})$ derivates , $^{2,5-7}$ that generally show much higher photoluminescence efficiency and easy tunability of the emission energies, by introduction of substituents on the cyclometalated ligands $\left(\mathrm{C}^{\wedge} \mathrm{N}\right)$ or changing the coordinating ligands. Indeed, several examples of bis-cyclometalated $\operatorname{Ir}(\mathrm{III})$ complexes active as ECL luminophores in organic media with superior ECL intensity that commercial $\left[\mathrm{Ru}(\mathrm{bpy})_{3}\right]^{2+}$ have been described. ${ }^{2,8-10}$ However, only a few examples in aqueous media or aqueous/organic media have been reported, ${ }^{11-18}$ and the conditions described for the measurements are very different from those applied in commercial immunoassays analysis. $^{18-22}$

In this letter we report on the photoluminescence (PL) and ECL behavior of bis-cyclometalated $\operatorname{Ir}$ (III) complexes, [Ir$\left.\left(\mathrm{C}^{\wedge} \mathrm{N}\right)_{2}\left(\mathrm{~L}^{\wedge} \mathrm{X}\right)\right]\left(\mathrm{C}^{\wedge} \mathrm{N}=\right.$ cyclometalated ligand, $\mathrm{L}^{\wedge} \mathrm{X}=$ picolinate (pic), acetylacetonate (acac)), in organic solvent and in the

aqueous buffer solution (ProCell) used in commercial immunoassays. We show that modification of the $\mathrm{C}^{\wedge} \mathrm{N}$ ligand can lead to ECL efficiency higher than the commercial $\mathrm{Ru}$ based labels. In particular the complex, 5, based on phenylphenanthridine (pphent) as the $\mathrm{C}^{\wedge} \mathrm{N}$ ligand, shows a signal $\sim 3$ times higher than the standard luminophore, $\left[\mathrm{Ru}(\mathrm{bpy})_{3}\right]^{2+}$ under real ECL immunoassay conditions. To the best of our knowledge, this is the best performant $\operatorname{Ir}(\mathrm{III})$ complex in this condition.

The neutral cyclometalated Ir(III) complexes containing phenylpyridine-based ligands (Chart 1) were synthesized following modified procedures already described in the literature. ${ }^{23-25}$ For complex 4 we were able to obtain single crystals and X-ray crystal structure analysis data are reported in Figure S-1, Supporting Information.

Chart 1. Schematic Formulas of the Investigated Complexes

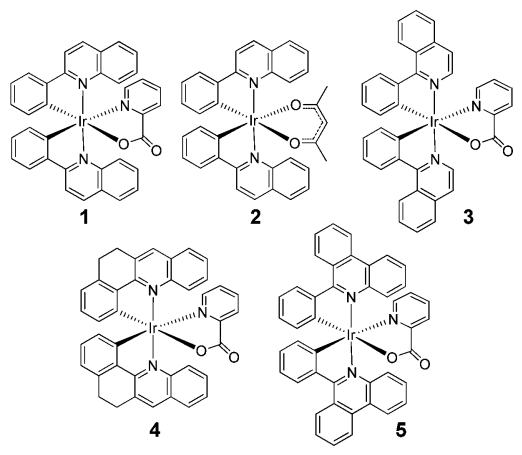

Received: January 24, 2016

Accepted: March 15, 2016

Published: March 15, 2016 
The photophysical characterization of the compounds was carried out both in $\mathrm{MeCN}$ and in ProCell solutions (Table 1

\section{Table 1. Photophysical Data for the Investigated Complexes}

\begin{tabular}{|c|c|c|c|c|}
\hline complex & solvent & $\lambda_{\mathrm{em}}(\mathrm{nm})$ & $\mathrm{QY}_{\text {dear }} / \mathrm{QY}_{\text {aer }}(\%)$ & $\tau_{\text {deaer }} / \tau_{\text {aer }}(\mu \mathrm{s})$ \\
\hline \multirow[t]{2}{*}[\mathrm{Ru}(\mathrm{bpy})_{3}]{$^{2+}$} & $\mathrm{MeCN}$ & $611^{b}$ & $6.2^{b} / 1.6^{b}$ & $0.99^{b} / 0.17^{b}$ \\
\hline & ProCell $^{a}$ & 624 & $-/ 5$ & 0.40 \\
\hline \multirow[t]{2}{*}{1} & $\mathrm{MeCN}$ & 589 & $70 / 3$ & $1.99 / 0.08$ \\
\hline & ProCell $^{a}$ & 584 & $-/ 20$ & $-/ 0.62$ \\
\hline \multirow[t]{2}{*}{2} & $\mathrm{MeCN}$ & 612 & $59 / 2$ & $1.81 / 0.06$ \\
\hline & ProCell $^{a}$ & 609 & $-/ 11$ & 0.47 \\
\hline \multirow[t]{2}{*}{3} & $\mathrm{MeCN}$ & 613 & $40 / 3.5$ & $1.74 / 0.14$ \\
\hline & ProCell $^{a}$ & 610 & $-/ 15$ & $-/ 0.72$ \\
\hline \multirow[t]{2}{*}{4} & $\mathrm{MeCN}$ & 583 & $70 / 3$ & $1.95 / 0.07$ \\
\hline & ProCell $^{a}$ & 578 & $-/ 18$ & $-/ 0.55$ \\
\hline \multirow[t]{2}{*}{5} & $\mathrm{MeCN}$ & 648 & $27 / 3$ & $1.69 / 0.19$ \\
\hline & ProCell $^{a}$ & 645 & $-/ 14$ & $-/ 0.74$ \\
\hline
\end{tabular}

${ }^{a}$ The complexes were dissolved in $1 \mathrm{~mL}$ of DMSO and $10 \mu \mathrm{L}$ of this solution was diluted in $10 \mathrm{~mL}$ of ProCell solution to reach a concentration $10^{-6} \mathrm{M} .{ }^{b}$ Data from literature. ${ }^{29}$

and Supporting Information S-2). The comparison of the two solvents is indeed important to understand the role of the media, since the luminescence properties are different (see below) in the ProCell used for the ECL experiments. We can assume that the luminescent state generated by photon excitation is the same as the one generated by ECL, ${ }^{2}$ and therefore we can quantify the effects of the components of the ProCell solution (phosphate buffer containing TPA and a nonionic surfactant) on the emissive excited state (see below).

The absorption spectra of the complexes in $\mathrm{MeCN}$ (Supporting Information, Figure S-2) exhibit intense bands in the UV region $\left(\lambda_{\mathrm{abs}}=210-400 \mathrm{~nm}\right)$ with molar extinction coefficients $(\varepsilon) \sim 10^{5} \mathrm{M}^{-1} \mathrm{~cm}^{-1}$ that are assigned to the $\pi-\pi^{*}$ transition localized on the coordinated ligands, and weaker bands at longer wavelength $(420-580 \mathrm{~nm})$ assigned to spinallowed and spin-forbidden singlet and triplet metal-to-ligand charge transfer (MLCT) transitions. ${ }^{24,25}$

The complexes are all luminescent in solution at room temperature and show emission maxima in the orange to red region of the visible spectra $(583-648 \mathrm{~nm})$ both in deaerated and air-equilibrated solutions in $\mathrm{MeCN}$ (Table 1, Supporting Information Figure S-3). It is known that bis-cyclometalated $\operatorname{Ir}(\mathrm{III})$ compounds as $\left[\operatorname{Ir}\left(\mathrm{C}^{\wedge} \mathrm{N}\right)_{2}\left(\mathrm{~L}^{\wedge} \mathrm{X}\right)\right]\left(\mathrm{L}^{\wedge} \mathrm{X}=\right.$ pic or acac $)$ exhibit room-temperature phosphorescence spectra that are mainly metal to ligand charge transfer in character. The energy of the emission is dictated by the LUMO and HOMO localized on the $\operatorname{Ir}\left(C^{\wedge} N\right)_{2}$ fragment, when the energy gap of the $L^{\wedge} X$ ligand are sufficiently higher compared to the $C^{\wedge} N$ ligand. ${ }^{24,26}$ Therefore, substitution of the cyclometalated ligand, and in our case, the $\pi$-electron system of the $\mathrm{N}$-heterocycle is extended in the series 1,3 , and 5 causing a red shift on the emission wavelengths compared to the analogous phenylpyridine complex (Table 1). ${ }^{27}$ The excited state lifetimes in deaerated solutions decay with a monoexponential kinetics and are in the range of microseconds $(1.69-1.99 \mu \mathrm{s})$, typical for this type of complex. ${ }^{24,25,28}$ Emission quantum yields (QYs) in deaerated $\mathrm{MeCN}$ are between $27 \%$ and $70 \%$ increasing in the order $1>4$ $>\mathbf{2}>\mathbf{3}>\mathbf{5}$ (Table 1). Complexes $\mathbf{1}$ and $\mathbf{4}$ present similar QYs and excited state lifetimes and a very small shift of the emission maximum revealing no effects of the annulation of the phenyl and quinoline rings in 4 .
The piq derivate 3, has a lower QY (40\%) and slightly shorter lifetime than its isomer $\mathbf{1}$. Complex $\mathbf{5}$, showing the most pronounced red-shift of the emission, in agreement with the "energy gap law", is characterized by the lowest QY in deaerated solution $(27 \%)$ and the shortest excited state lifetime $(1.69 \mu \mathrm{s})$. Interestingly, the QYs values found for complexes 1 $(70 \%)$ and 2 (59\%) are significantly higher than those described in the literature, $27 \%{ }^{25}$ and $10 \%,{ }^{24,25}$ respectively. In aerated solutions, both the excited state lifetimes and the emission quantum yields decrease, compared with the deaerated conditions, due to the triplet nature of the emitting states in all these complexes, quenched by dioxygen.

The emission profiles of the complexes in $\mathrm{MeCN}$ correlate well with those in ProCell, although the maxima are slightly blue-shifted $(\sim 3-10 \mathrm{~nm})$ in the latter (Table 1 and Figure S-3, Supporting Information). Interestingly in aerated ProCell solution, the compounds possess rather long excited state lifetimes and decay monoexponentially, and they are highly emissive (QYs up to 20\%) (Table 1). The fact that the emissive properties are remarkable better than those observed in aerated $\mathrm{MeCN}$ suggests that the quenching of the emission by dioxygen is smaller in ProCell media. Such effect cannot be only related to the different amount of dioxygen present in the solvents, which is indeed higher in the organic solvent but also due to a different exposure to the quencher. Indeed one possible explanation for this shielding to the dioxygen could be the entrapping of the complexes in micelles, ${ }^{28}$ due to the presence of the surfactant in ProCell in a concentration way above its critical micellar concentration (CMC). The confinement of the complexes in micelles could also explain the observed blue-shift in the emission spectra since the apolar complexes will tend to be encapsulated in the hydrophobic pocket and therefore the environment is less polar than the $\mathrm{MeCN}$ or the plain water. Moreover, all our complexes show, in ProCell solution, higher photoluminescence QYs than $\left[\mathrm{Ru}(\mathrm{bpy})_{3}\right]^{2+}(\mathrm{QY}=5 \%)$, the luminophore used in commercial aqueous media immunoassays $^{2}$ that do not show a significant improvement going from PBS solution containing TPA ( $Q Y=5 \%)$ to ProCell solutions. On the other hand complex $\mathbf{5}$ has an emission quantum yield that increases going from PBS in the presence of TPA to ProCell ( $Q Y=8 \%$ and $14 \%$, respectively). We believe that the rigidity and the hydrophobic character of the complex determine its better encapsulation in the ProCell media. We could therefore expect higher ECL efficiency once the excited state is formed, assuming a similar mechanism, for the iridium derivatives, as that involving the ruthenium complex. Thus, we have investigated the spectroscopic behavior of such a kind of Ir(III) complexes under ECL aqueous media immunoassay conditions using both a homemade system and the commercial instrument ELECSYS 2010.

To reach the formation of the excited state by electrochemiluminescence, we must tune the redox properties of the complexes in order to oxidize and reduce the emitter in the range useful for the TPA employed as coreactant. The electrochemical properties of the complexes were therefore studied by cyclic voltammetry $(\mathrm{CV})$ in oxygen-free $\mathrm{MeCN}$ (Table 2 and Supporting Information S-3). Interestingly, the standard oxidation potentials $\left(E_{\text {oxd }}^{\circ}\right)$ of the compounds are within a short-range from $+1.07 \mathrm{~V}$ to $+0.93 \mathrm{~V}$ vs SCE, and they correlate well with those already described in the literature. It can be noticed that the extension of the $\pi$-system on the pyridine ring, of the cyclometalated ligand, has almost no effects on the oxidation potential. For complexes of the type 
Table 2. Electrochemical and Electrochemiluminescent Properties of the Complexes

\begin{tabular}{|c|c|c|c|c|c|}
\hline complex & $\begin{array}{c}E^{\circ}{ }_{o x d} E^{\circ} \text { red } \\
(\mathrm{V})^{a}\end{array}$ & $\begin{array}{l}E \text { vs } \\
\mathrm{ECL} \\
(\mathrm{V})^{b}\end{array}$ & $\begin{array}{c}\lambda_{\text {em }}(\mathrm{nm}) \\
\text { vs ECL }\end{array}$ & $\begin{array}{c}\mathrm{ECL}^{c} \\
I_{\text {complex }} / I_{\mathrm{Ru}}\end{array}$ & $\begin{array}{c}\text { ECL } \\
\text { counts }\end{array}$ \\
\hline$\left[\mathrm{Ru}(\mathrm{bpy})_{3}\right]^{2+}$ & $\begin{array}{l}+1.35^{g} \\
-1.33,^{g} \\
-1.52^{g} \\
-1.76^{g}\end{array}$ & $\begin{array}{l}+0.96 \\
+1.16\end{array}$ & 624 & & 10000 \\
\hline 1 & $\begin{array}{l}+1.06 \\
-1.62 \\
-1.86\end{array}$ & +0.96 & 598 & $0.50 \pm 0.04$ & 5699 \\
\hline 2 & $\begin{array}{l}+0.93 \\
-1.65 \\
-1.74\end{array}$ & +1.02 & 612 & $0.11 \pm 0.03$ & 1069 \\
\hline 3 & $\begin{array}{l}+1.05 \\
-1.61 \\
-1.83\end{array}$ & +0.94 & 615 & $0.21 \pm 0.01$ & 2168 \\
\hline 4 & $\begin{array}{l}+1.05 \\
-1.63 \\
-1.86\end{array}$ & +0.96 & 593 & $0.67 \pm 0.03$ & 3963 \\
\hline 5 & $\begin{array}{l}+1.07 \\
-1.48 \\
-1.77\end{array}$ & $\begin{array}{l}+0.94 \\
+1.05 \\
+1.24\end{array}$ & 649 & $3.72 \pm 0.04$ & 28485 \\
\hline
\end{tabular}

${ }^{a}$ Values vs SCE. ${ }^{b} \mathrm{Ag} / \mathrm{AgCl}(1 \mathrm{M} \mathrm{KCl}) . \mathrm{ECL}$ in $50 \mu \mathrm{M}$ in ProCell (25 $\mu \mathrm{L}$ of DMSO solution of the complex in $5 \mathrm{~mL}$ of ProCell). Working electrode $=$ glassy carbon, reference electrode $=\mathrm{Ag} / \mathrm{AgCl}(1 \mathrm{M} \mathrm{KCl})$. ${ }^{c}$ Home-made system. Stepwise potential $E_{1}=0 \mathrm{~V}$ for $t_{1}=1 \mathrm{~s} ; E_{2}=1.4$ $\mathrm{V}$ for $t_{2}=1 \mathrm{~s}$. Integration of the first wave of the photocurrent and compared to $\left[\mathrm{Ru}(\mathrm{bpy})_{3}\right]\left(\mathrm{PF}_{6}\right)_{2}\left(I_{\text {complex }} / I_{[\mathrm{Ru}(\mathrm{bpy}) 3] 2+}\right)$. The error is given as standard deviation of three different measurements. ${ }^{a}$ Commercial system ELECSYS 2010 analyzer, $\left[\mathrm{Ru}(\mathrm{bpy})_{3}\right]\left(\mathrm{PF}_{6}\right)_{2}$ as reference (Supporting Information). ${ }^{g}$ Data from the literature. ${ }^{32}$

$\left[\operatorname{Ir}\left(\mathrm{C}^{\wedge} \mathrm{N}\right)_{2}\left(\mathrm{~L}^{\wedge} \mathrm{X}\right)\right]^{25,30}$ the oxidation is assumed to be metal-aryl centered, and it is therefore directly affected by different substitution on the aryl group or by the type of ancillary ligand, $\mathrm{L}^{\wedge} \mathrm{X}{ }^{31}$ Complexes with pic as ancillary ligand a certain amount of HOMO is localized on the carboxylate and 1, 3, 4, and 5 with no significant changes in the metal-aryl part, show very similar oxidation potential $(+1.06 \mathrm{~V},+1.05 \mathrm{~V},+1.05 \mathrm{~V},+1.07$ $\mathrm{V})$, while complex 2 has different oxidation potential $(+0.93 \mathrm{~V})$. The oxidation processes are reversible at a scan rate of $0.1 \mathrm{~V} / \mathrm{s}$, except for $\mathbf{5}$ whose reversibility is only observed at scan rates higher than $0.5 \mathrm{~V} / \mathrm{s}$. In the reduction, all the complexes exhibit two reversible reduction waves corresponding, each one, to a monoelectronic process (Table 2 and Supporting Information $\mathrm{S}-3)$. As described in the literature, these waves can be assigned to the reduction of the $\mathrm{N}$-heterocyclic ring of the cyclometalated ligand. ${ }^{25}$ Thus, for complexes 1,3 , and 4 the values of the first and second reduction are almost identical, -1.6 and $-1.8 \mathrm{~V}$, respectively (Table 2 ), while for $\mathbf{5}$, a lower reduction potential is observed $(-1.48 \mathrm{~V}$ and $-1.77 \mathrm{~V})$ due to an extension of conjugation in the heterocyclic ring. The acac derivate, 2, shows a slightly higher reduction potential than its picolinate analogue.

The ECL activity of the $\operatorname{Ir}(\mathrm{III})$ compounds were evaluated studying ECL intensities as a function of voltage applied, time and emission profile, and intensity. For a solution of $50 \mu \mathrm{M}$ $\left[\mathrm{Ru}(\mathrm{bpy})_{3}\right]^{2+}$ in ProCell, two broad waves, $+0.96 \mathrm{~V}$ and +1.16 $\mathrm{V}$ vs $\mathrm{Ag} / \mathrm{AgCl}(1 \mathrm{M} \mathrm{KCl})$ are observed (Supporting Information S-4). These values are in agreement with those reported by Bard et al. for the system $\left[\mathrm{Ru}(\mathrm{bpy})_{3}\right]^{2+} / \mathrm{TPA}$ in aqueous solution containing $\left[\mathrm{Ru}(\mathrm{bpy})_{3}\right]^{2+}$ in low concentration compared to TPA (micromolar range to $\sim 0.1 \mathrm{M}$ )..$^{33,34}$ Both waves are associated with the generation of the excited state of $\left[\mathrm{Ru}(\mathrm{bpy})_{3}\right]^{2+}$. However, the first wave occurs when $\mathrm{TPA}^{\bullet+}$, formed upon oxidation of TPA, oxidizes $\left[\mathrm{Ru}(\mathrm{bpy})_{3}\right]^{+}$ (generated by reduction of $\left[\mathrm{Ru}(\mathrm{bpy})_{3}\right]^{2+}$ by TPA free radical) to give the excited state of $\left[\mathrm{Ru}(\mathrm{bpy})_{3}\right]^{2+*}$, while the second wave is assigned to the classic coreactant mechanism (Supporting Information S-5). ${ }^{2,34}$ When our iridium complexes are studied in the same conditions, different behaviors are observed (Figure S-8, Supporting Information). In all the cases, the intensity of the wave is related to the ECL QY found for each investigated compound (see below). Complexes 1, 4, and 3 exhibit only a single intense peak at $+0.96 \mathrm{~V},+0.96 \mathrm{~V}$, and $+0.94 \mathrm{~V}$ vs Ag/AgCl $(1 \mathrm{M} \mathrm{KCl})$, respectively. These values are similar to those reported for the oxidation of TPA (see above), ${ }^{35,36}$ and slightly lower than those corresponding to the electrochemical oxidation of the complexes (after correction for the $\mathrm{Ag} / \mathrm{AgCl}$ reference electrode) (Table 2 and Table S-2, Supporting Information S-4). For complex 2 the intensity of the signal is much lower and the wave is broader at $+1.02 \mathrm{~V}$, a value higher than the electrochemical oxidation potential of the complex. Finally, complex $\mathbf{5}$ exhibits the most intense signal of the series and, interestingly, three waves at $+0.95 \mathrm{~V},+1.05 \mathrm{~V}$, and $+1.24 \mathrm{~V}$ vs $\mathrm{Ag} / \mathrm{AgCl}(1 \mathrm{M} \mathrm{KCl})$ are observed. The first wave appears at almost same value as in $\left[\mathrm{Ru}(\mathrm{bpy})_{3}\right]^{2+}, \mathbf{1}, \mathbf{4}$, and 3 and can be assigned to the oxidation of the TPA. Thus, we believe that the process involved in the generation of light is similar as the one reported for $\left[\mathrm{Ru}(\mathrm{bpy})_{3}\right]^{2+}$, i.e. involving the formation of the excited state on reaction of $\mathrm{TPrA}^{\bullet+}$ with reduced iridium complex (formed by reaction of neutral iridium complex with $\operatorname{TPrA}^{\bullet}$ ) (Supporting Information S-5). ${ }^{34}$ The second wave value matches with the oxidation potential of the complex, suggesting that the mechanism involves the classic oxidative-reduction coreactant mechanism that is the direct oxidation of the complex on the electrode surface. ${ }^{32}$ Further investigation is currently ongoing to understand the nature of the third one.

We also quantified the ECL efficiency of our complexes with respect to the standard $\left[\mathrm{Ru}(\mathrm{bpy})_{3}\right]^{2+}$ looking at the ECL emission vs time in ProCell (Table 2). In this experiment, the ECL was generated by a chronoamperometry pulse at $+1.4 \mathrm{~V}$ for $1 \mathrm{~s}$ and the light detected using a photomultiplier tube (PMT) (Figure S-9, Supporting Information S-4). Table 2 shows the relative ECL intensities of the complexes compared to $\left[\mathrm{Ru}(\mathrm{bpy})_{3}\right]^{2+}$ system, $I_{\text {complex }} / I_{\mathrm{Ru}}$, where $I_{\text {complex }}$ is the integrated signal of the complex analyzed and $I_{\mathrm{Ru}}$ is the integrated signal of $\left[\mathrm{Ru}(\mathrm{bpy})_{3}\right]^{2+}$ under the same conditions. The intensity changes along the series of picolinate derivates, increasing in the order $5>\mathbf{4}>\mathbf{1}>\mathbf{3}>\mathbf{2}$. Surprisingly, complex 2, which exhibits the higher ECL QY described in the literature for the coreactant method in organic media (77 times more emissive than $\left.\left[\mathrm{Ru}(\mathrm{bpy})_{3}\right]^{2+}\right],^{14,25,28}$ decreases dramatically its efficiency $\left(0.11\right.$ times $\left.\left[\mathrm{Ru}(\mathrm{bpy})_{3}\right]^{2+}\right)$ when used under immunoassay conditions. Recently, Kim et al. have evaluated the ECL of complex 2/TPA system for quantitative analysis in flowing streams in buffer/MeCN (1:1) solutions, claiming a more efficient ECL than the conventional $\left[\mathrm{Ru}(\mathrm{bpy})_{3}\right]^{2+}$ system. ${ }^{14}$ However, in our hands, this complex clearly failed to reach this value. A similar behavior is observed for 1 , whose emission falls from 26 times in organic media to 0.50 times the intensity of $\left[\mathrm{Ru}(\mathrm{bpy})_{3}\right]^{2+}$, when used under immunoassay conditions. The piq derivate 3 shows a value of 0.21 times 
$\left[\mathrm{Ru}(\mathrm{bpy})_{3}\right]^{2+}$, and the emission does not improve with respect to its isomer 1. Complex 4 shows an ECL value in between 1 and 3. Interestingly, the most successful complex is $\mathbf{5}$ that exhibits 3.7 times higher emission than $\left[\mathrm{Ru}(\mathrm{bpy})_{3}\right]^{2+}$ (Supporting Information S-4, Figure S-9). To the best of our knowledge this is the best result for an iridium complex in biologically compatible buffer solution, ${ }^{13}$ providing a real alternative to $\left[\mathrm{Ru}(\mathrm{bpy})_{3}\right]^{2+}$ as an ECL label.

Encouraged by these results, we further studied the behavior of our complexes under true commercial ECL immunoassay conditions $^{21,23}$ using a commercial instrument ELECSYS 2010 and following the standard procedure for immunoassays, i.e., nanomolar concentration of the complex in ProCell solution but in the absence of streptavidin-coated paramagnetic microparticles (see Supporting Information).

The values observed reproduce well those obtained with the homemade system. Again, the best complexes in organic media, 2 and 1 , have a poor performance and show an intensity of 0.1 and 0.7 times the signal of $\left[\mathrm{Ru}(\mathrm{bpy})_{3}\right]^{2+}$, respectively. However, complex $\mathbf{5}$ has a signal that is 2.8 times the intensity of the $\left[\mathrm{Ru}(\text { bpy })_{3}\right]^{2+}$, confirming that it is a good candidate for immunoassays. Finally, we also studied the ECL spectra of the complexes in our homemade system to evaluate the nature of the emissive excited state generated by this process. The spectra were collected using a cooled EMCCD camera with the accumulation of $10 \mathrm{~s}$ while pulsed potential was applied between $0 \mathrm{~V}$ and $+1.4 \mathrm{~V}$ (see the Supporting Information). Under these conditions, the obtained ECL spectra are almost identical to the PL spectra measured in ProCell and $\mathrm{MeCN}$ solutions (Figure S-10, Supporting Information S-4), confirming that the ECL and PL emissions come from the same excited state.

In summary, a series of neutral bis-cyclometalated iridium(III) complexes based on the structure $\left[\operatorname{Ir}\left(\mathrm{C}^{\wedge} \mathrm{N}\right)_{2}(\mathrm{LX})\right]$ have been described and their PL and ECL properties in aqueous buffer medium studied. We observed that complexes $\mathbf{1}$ and 2, which were described in the literature as very efficient ECL label in organic solutions, exhibit a dramatic performance decrease in an aqueous media similar to immunoassay analysis. Moreover we demonstrate that the modification of the cyclometalated ligand, as in complex $\mathbf{5}$, increases significantly the ECL QY up to $\sim 3$ times the intensity of the complex $\left[\mathrm{Ru}(\mathrm{bpy})_{3}\right]\left(\mathrm{PF}_{6}\right)_{2}$ employed in commercial equipment. The high ECL performance of $\mathbf{5}$ in aqueous buffer suggests that, for the first time, we could replace the commercial ruthenium label with a more sensitive iridium one for immunoassays. Further investigations are ongoing in order to unravel the effect on ECL of different modification on either the phenanthridine and/or phenyl ring in the pphent ligand, aiming to rationalize the relationship structure-ECL efficiency.

\section{ASSOCIATED CONTENT}

\section{S Supporting Information}

The Supporting Information is available free of charge on the ACS Publications website at DOI: 10.1021/acs.analchem.6b00312.

Supporting figures and synthesis and experimental methods (PDF)

\section{AUTHOR INFORMATION}

\section{Corresponding Authors}

*E-mail: decola@unistra.fr.
*E-mail: hans-peter.josel@roche.com.

\section{Present Addresses}

${ }^{\S}$ E.L. and L.D.C.: Institut de Science et d'Ingénierie Supramoléculaires (I.S.I.S.), Université de Strasbourg, 8 Allée Gaspard Monge, 67000 Strasbourg, France.

\#J.M.F.-H.: Grupo de Química Organometálica, Departamento de Química Inorgánica, Facultad de Química, Universidad de Murcia, Apdo. 4021,30071 Murcia, Spain.

"F.P.: Department of Experimental and Clinical Pharmacology Unit, CRO - National Cancer Institute, Via Franco Gallini 2, 33081 Aviano, Italy.

\section{Notes}

The authors declare no competing financial interest.

\section{ACKNOWLEDGMENTS}

The authors thank Dr. Roland Fröhlich for the X-ray analysis of one of the complex. J.M.F.-H., E.L., and L.D.C. acknowledge Roche Diagnostics for financial support.

\section{REFERENCES}

(1) Bard, A. J., Ed. Electrogenerated Chemiluminescence; Marcel Dekker: New York, 2004.

(2) Miao, W. Chem. Rev. 2008, 108, 2506.

(3) Zhou, M.; Robertson, G. P.; Roovers, J. Inorg. Chem. 2005, 44, 8317-8325. Rubinstein, I.; Bard, A. J. J. Am. Chem. Soc. 1981, 103, $512-516$.

(4) Qin, J.; Deng, S.-Y.; Qian, C.-X.; Li, T.-Yi.; Ju, H.-X.; Zuo, J.-L. J. Organomet. Chem. 2014, 750, 7. Doeven, E. H.; Zammit, E. M.; Barbante, G. J.; Francis, P. S.; Barnett, N. W.; Hogan, C. F. Chem. Sci. 2013, 4, 977.

(5) Reid, E. F.; Burn, P. L.; Lo, S.-C.; Hogan, C. F. Electrochim. Acta 2013, 100, 72.

(6) Ladouceur, S.; Swanick, K. N.; Gallagher-Duval, S.; Ding, Z.; Zysman-Colman, E. Eur. J. Inorg. Chem. 2013, 2013, 5329.

(7) Swanick, K. N.; Ladouceur, S.; Zysman-Colman, E.; Ding, Z. RSC Adv. 2013, 3, 19961.

(8) Stringer, B. D.; Quan, L. M.; Barnard, P. J.; Wilson, D. J.; Hogan, C. F. Organometallics 2014, 33 (18), 4860.

(9) Swanick, K. N.; Ladouceur, S.; Zysman-Colman, E.; Ding, Z. Chem. Commun. 2012, 48, 3179.

(10) Zhou, Y.; Li, W.; Yu, L.; Liu, Y.; Wang, X.; Zhou, M. Dalton Trans. 2015, 44, 1858.

(11) Barbante, G. J.; Doeven, E. H.; Kerr, E.; Connell, T. U.; Donnelly, P. S.; White, J. M.; Lopes, T.; Laird, S.; Wilson, D.J. D.; Barnard, P. J.; Hogan, C. F.; Francis, P. S. Chem. - Eur. J. 2014, 20, 3322.

(12) Tong, B.; Ma, P.; Mei, Q.; Hua, Z. Inorg. Chim. Acta 2014, 421, 405.

(13) Yu, L.; Huang, Z.; Liu, Y.; Zhou, M. J. Organomet. Chem. 2012, $718,14$.

(14) Shin, I.-S.; Kang, Y.-T.; Lee, J.-K.; Kim, H.; Kim, T. H.; Kim, J. S. Analyst 2011, 136, 2151.

(15) Li, M.-J.; Jiao, P.; Lin, M.; He, W.; Chen, G.-N.; Chen, X. Analyst 2011, 136, 205.

(16) Zanarini, S.; Felici, M.; Valenti, G.; Marcaccio, M.; Prodi, L.; Bonacchi, S.; Contreras-Carballada, P.; Williams, R. M.; Feiters, M. C.; Nolte, R. J. M.; De Cola, L.; Paolucci, F. Chem. - Eur. J. 2011, 17, 4640.

(17) Li, C.; Lin, J.; Guo, Y.; Zhang, S. Chem. Commun. 2011, 47, 4442.

(18) Li, C.; Lin, J.; Yang, X.; Wan, J. J. Organomet. Chem. 2011, 696, 2445.

(19) Shu, Q.; Birlenbach, L.; Schmittel, M. Inorg. Chem. 2012, 51, 13123.

(20) Yu, L.; Huang, Z.; Liu, Y.; Zhou, M. J. Organomet. Chem. 2012, $718,14$.

(21) Hoyle, N.; Eckert, B.; Kraiss, S. Clin. Chem. 1996, 42, 1576. 
(22) Staffilani, M.; Höss, E.; Giesen, U.; Schneider, E.; Hartl, F.; Josel, H.-P.; De Cola, L. Inorg. Chem. 2003, 42, 7789.

(23) Gassner, D.; Stock, W.; Golla, R.; Roth, H.-J. Clin. Chem. Lab. Med. 2009, 47, 1091.

(24) Lamansky, S.; Djurovich, P.; Murphy, D.; Abdel-Razzaq, F.; Kwong, R.; Tsyba, I.; Bortz, M.; Mui, B.; Bau, R.; Thompson, M. E. Inorg. Chem. 2001, 40, 1704.

(25) Shin, I.-S.; Kim, J. I.; Kwon, T.-H.; Hong, J.-I.; Lee, J.-K.; Kim, H. J. Phys. Chem. C 2007, 111, 2280.

(26) Chi, Y.; Chou, P. T. Chem. Soc. Rev. 2010, 39, 638.

(27) Hwang, F.-M.; Chen, H.-Y.; Chen, P.-S.; Liu, C.-S.; Chi, Y.; Shu, C.-F.; Wu, F.-I.; Chou, P.-T.; Peng, S.-M.; Lee, G.-H. Inorg. Chem. 2005, 44, 1344.

(28) Kim, J. I.; Shin, I.-S.; Kim, H.; Lee, J.-K. J. Am. Chem. Soc. 2005, $127,1614$.

(29) Issberner, J.; Vogtle, F.; De Cola, L.; Balzani, V. Chem. - Eur. J. 1997, 3 (5), 706.

(30) Guerrero-Martinez, A.; Vida, Y.; Dominguez-Gutierrez, D.; Albuquerque, R. Q.; De Cola, L. Inorg. Chem. 2008, 47, 9131.

(31) Lee, W.; Kwon, T.-H.; Kwon, J.; Kim, J.-y.; Lee, C.; Hong, J.-I. New J. Chem. 2011, 35, 2557.

(32) Tokel-Takvoryan, N. E.; Hemingway, R. E.; Bard, A. J. J. Am. Chem. Soc. 1973, 95, 6582.

(33) Fantacci, S.; De Angelis, F. Coord. Chem. Rev. 2011, 255, 27042726

(34) Zu, Y.; Bard, A. J. Anal. Chem. 2000, 72, 3223.

(35) Miao, W.; Choi, J.-P.; Bard, A. J. J. Am. Chem. Soc. 2002, 124, 14478

(36) Lai, R. Y.; Bard, A. J. J. Phys. Chem. A 2003, 107, 3335. 